\title{
Educational Game Software Design Patterns Based On Experiential Learning
}

\author{
Shufeng Zhang ${ }^{1}$, Zheng Liu ${ }^{1}$ \\ ${ }^{1}$ Suzhou Industrial Park Institute of Services Outsourcing, Suzhou, Jiangsu, China
}

Keywords: experiential learning; educational games; game software; software design

\begin{abstract}
Teaching games combine games with teaching to enable students to learn the knowledge and skills required by teaching objectives in the process of playing games. This paper first briefly introduces the characteristics of the teaching game and the characteristics of experiential learning, and then introduces the mode construction of the experiential educational game and the design of the game software.
\end{abstract}

\section{Introduction}

Educational games are a new way of teaching in the modern information and digital society to learn in the game, which can effectively improve the learning efficiency of students. Educational games, through the nature of students' love of play, enable students to learn while playing, thereby effectively improving students' interest in learning and improving the quality of students' learning. Educational games have emerged in the needs of modern real education, which not only meet the needs of students to play, but also enable students to learn new knowledge while playing [1].

Experiential learning refers to students learning different research examples according to their interests, hobbies and conditions under the guidance of teachers, conducting research independently and independently, and cultivating a learning style of exploring spirit and creativity. The outstanding feature of this learning style is to adhere to the students' free choice of topics in the learning process, independent research and free creation [1]. Compared with the previous learning methods, experiential learning is more conducive to stimulating students' enthusiasm for solving problems and cultivating students' innovation. In the teaching of game software, we try to use the essence of experiential learning, hoping to cultivate students' independent research and practice ability, allowing students to explore problems, collect materials, explore, analyze and study self-selected topics through experiential learning [1]. Finally, in the practice of training students' scientific attitudes and values as well as innovative spirit, innovative thinking, creativity, and learning to solve related practical problems.

\section{Characteristics of Educational Games and Experiential Learning}

\subsection{Features of educational games.}

Each game has a defined goal and a set of pre-defined rules to show how the game be played, that is: what can be done, what can be done, what kind of rewards can be won, what is a victory, and so on.

\subsection{Competitive and challenging factors.}

For many students, competition and challenges make the game fun and exciting. On the road to the goal, students must compete with their opponents (which can be computers, gamers themselves or other students), and on the other hand, overcome difficulties, remove obstacles, and face various challenges [1].

Closely related to other CAI methods, it uses in multiple stages of the teaching process. In fact, many scenario behavior simulations have the components of the game, and the teaching simulation used in all stages of the teaching process, so the teaching game may also have similar effects. For example, you can design an exercise as a teaching game. The simplest application of the game during the teaching process is as reinforcement for the student. 


\subsection{Experiential learning.}

1) Pay attention to the presentation and solution of problems. In experiential learning, teachers must first organize students to select and determine the research topics they are interested in from study and life. In experiential learning, the problem is an important carrier for students' learning [2]. In the process of solving problems, a variety of knowledge is involved. The selection, accumulation and application of this knowledge are completely problem-oriented and present a horizontal and inter-crossing state.

2) Pay attention to students' self-learning. Experiential learning is not to learn book knowledge, but to emphasize the practice process of manual brain. It does not rely solely on teachers to impart knowledge and skills, but emphasizes the behavior and process of students' self-learning. In the current teaching, the learning style of students is accepting learning, but the learning of knowledge only internalized into the students' own experience system through independent learning. In experiential learning, it is through the creation of similar scientific research scenarios that allow students to experience, practice, develop and experience independently, thus cultivating students' scientific spirit, innovative thinking and ability to analyze and solve problems [2]. Moreover, I pay attention to guiding students to explore hierarchical tasks in specific applications. They encourage students with sense of accomplishment and difficult tasks to attract students to continue to explore.

3) Pay attention to the openness of students' learning content and learning time. The openness of experiential learning refers to the non-closed nature between the elements that constitute experiential learning and the elements involved in the implementation process, which is concentrated in the opening of learning content. The learning content of experiential learning is multi-faceted, and experiential learning obviously has more time.

4) Emphasis on communication and collaboration among students. Since experiential learning is problem-solving learning, students faced with complex and comprehensive problems, which depend on students' supply price wisdom and division of labor [2]. This kind of communication and collaboration includes the spirit of communication and collaboration, the ability to communicate and collaborate, such as mutual respect, understanding and tolerance, ways and means of expressing, listening and persuading others, and the ability to formulate and implement collaborative research programs.

\section{The Basic Structure of Educational Game Software Based on Experiential Learning}

\subsection{Import section design.}

In the import section, you need to explain to students the goals and rules of the teaching game and need to teach them how to operate it. The rules of the game are artificial made, but in the teaching game software, the user cannot change the rules [3]. It stipulates the status of the game, the equipment used, the procedures allowed, and the penalties imposed. Some games specifically set up a drop-down menu.

The rules tell the students what to do, and the instructions indicate the details related to completing the actions. This content is usually stored in the Help Information by setting the menu below.

\subsection{Student choice.}

Students can make many choices before the game officially begins. The content choose from usually includes: the role the student plays in the game, the difficulty of the game, and the speed of the student's movements (which can be seam as an aspect of difficulty) [2]. In addition, sometimes you can choose whether to play the game opponent by the computer.

\subsection{End section design.}

When the game process is over, the game system should transfer to the final section. At this time, the main work of the system includes confirming the winner, awarding the prize and providing after-care information.

Confirmation of the winner refers to the name of the system that decides the outcome according to 
the established rules and announces the victory. Some games have no wins and losses, and the system only gives the scores obtained by the players [3]. It sometimes pointed out that the score is in the position of all previous players' scores, i.e. relative rankings. However, if the system needs to store this data for reference by other players, then the player's own consent obtained.

For players who win, the system should be encouraged. For example, play a song "Kai Ge" or display a very interesting animation.

For those who do not use the best strategy in the game, the system should tell him his personal performance and the best results of others, so that he understands his gap. Some games store the whole process of a good player's game, so that players with poor grades can ask the system to display the process, thereby gaining inspiration and changing their game strategy.

Finally, the system should generally also allow students to choose between continuing to play the game and exiting the game. If the student decides to quit, the system should first give clear information about the end of the game, and then quit to avoid the student's misunderstanding of system failure.

\section{Design of Educational Game Software Based on Experiential Learning}

The design model of educational game software bases on experiential learning design ideas, design patterns, design processes, and design methods. Scientific selection, design, and combination of the components of the game performed [3]. Reasonable arrangement achieve the intuitive expression and presentation of experiential teaching design ideas, but also to better reflect and retain the positive elements of the game to education, thus achieving educational and game play in the design of educational game software.

The design of experiential learning has many angles. Because people choose different reference standards and different angles, they have different expressions for their design [4]. This paper mainly focuses on four aspects: learning objectives, learning content, learning strategies, and learning evaluation. Design the experiential learning of game software teaching.

\subsection{Design of learning objectives.}

The design of experiential learning objectives considered from the following two aspects:

First, it is complementary to the teaching of game software. Game software teaching emphasizes students' understanding and mastery of the basic knowledge of game software, while game software experiential learning does not pursue the teaching of the software subject knowledge [4]. It is based on the needs of student personality development, to explore the learning itself.

Second, it is the fundamental of learning the target itself. From this point of view, the idea of experiential learning is very similar to pure software teaching. The more it can become the basis of future learning, the more choice The value of the game software experiential learning is also more fundamental and general, and the more extensive the value of migration.

\subsection{Design of learning content.}

The specific selection and design of game software experiential learning content is mainly to reflect the learning objectives and learning principles of game software experiential learning [4]. There is no absolute standard and degree achieved, but it depends on the students and the school.

\subsection{Design of learning strategies.}

Experiential learning is a good way to communicate between school and society, books and practice, people and nature. On the one hand, game software experiential learning requires the participation of students' emotions and experience. On the other hand, it is the process of student's emotional development and new experience [5]. The acquisition of emotions and experience has a subtle influence on students' understanding and behavior, which is unmatched by pure software books. 


\subsection{Design of learning evaluation.}

Evaluation is the process of providing information for decision-making. The evaluation of experiential learning of game software refers to systematically collecting information in the process of experiential learning of game software, which caused by learning according to the requirements of learning objectives [5]. The change in cognitive behavior of students, the value judgment based on qualitative and quantitative, and the process of providing information for the decision-making of game software experiential learning.

\section{Design Example of Educational Game Software Based on Experiential Learning}

The content of the game software topical experiential learning is open and the form is diverse. This article takes the production of "Blender's 3D game" as an example to give a brief description of the experiential learning process.

\subsection{The content of the research example.}

Blender's superiority in making 3D games mainly reflected in the need to program, graphically to define the way of interaction. It not only simplifies the writing of the code, shortens the development time, but also provides opportunities for developers who are not good at code developers to develop $3 \mathrm{D}$ games. In addition to the three-dimensional features of Blender, the most prominent is that it is the only unified environment for 3D modeling and game production. It can simulate gravity, collision, force, acceleration, friction, etc. It can also create a series of 3D object types including: polygon mesh, NURBS surface, Bezier and B-splint curve, morph ball, vector font (TrueType, PostScript, Open Type) [6]. It also has great editing features such as extrusion, chamfering, shearing, rotation lofting, wrap around, subdivision, noise, and Python script customization tools.

In this study example, the game is a 3D maze game with logic and strategy. The player needs to move the box to the corresponding target position. The game sets multiple levels, sets three lives per level and has time [7]. If the player cannot finish the game within the specified time or if he has not used it for three times, then the game needs to be restarted. The player must successfully complete the previous level to enter the next level. The game structure is as follows:

1) Press the up, down, left, and right buttons on the keyboard to select the menu, and press the Enter key to select the currently selected menu.

2) Press the up, down, left, and right buttons on the keyboard to control the box to move forward, backward, left, and right.

3) Use the R key to rotate the window, the Q key to zoom in on the window, and the W key to zoom out the window.

4) Use the $C$ and V keys to switch the camera angle.

5) Cart: The game uses a cart to push the box. The arrow keys on the keyboard control the cart. Press the arrow button once to move the cart one-step. When the cart touches the wall that is not allowed crossing the wall.

6) Box: When the box collides with a wall or other box, it can no longer move. The game is specially equipped with some flammable and fragile items in the box. If these boxes collide with the wall, the game ends [6].

\subsection{Steps to study the examples.}

The implementation of the game software development teaching can be carried out in three stages [7]:

Stage 1: Preparation and guidance. Introduce the significance, general curriculum and precautions of the research on this topic, then arrange the topics to students and show examples of game software.

Phase 2: Design the project and conduct research. Let students collect information online, work together, carry out innovative design, and then conduct hands-on experiments, conduct research, and draw their own conclusions.

Stage 3: Evaluation and communication. Based on the teacher's review of the results of each group, 
students are organized to communicate.

1) Associated Objects

Associate the logical relationships in the Blender game engine to the corresponding objects. When the associated object is selected, the object's name is displayed in the logical window. A single associated object can be displayed in the logical window or multiple associated objects can be displayed.

2) Behavior

Behaviors are used to define objects that are unlikely to interact, such as environment objects, walls, or ground. These are usually fixed objects that are not affected by gravity in the game.

Behavior can be assigned to a variety of settings, such as gravity, volume, traces, and the like.

3) Properties

Attributes are like variables in other programming languages. Developers can add multiple properties to an object and set a unique name and type for each property [7]. They are very useful for storing extra information, such as the number of bullets remaining in a gun.

4) Sensors

Sensors are the core of the logical relationship. It is used to trigger events such as a key pressed on the keyboard, a timed event, and so on. When the sensor is triggered, it will pulse all linked controllers.

5) Controllers

The controller is used to determine how the multiple sensors interact and to determine when to switch to the Python scripting language.

6) Actuators

The brake affects parameters such as motion, sound, and attributes in the object or game.

7) Links

Links indicate the logical flow between objects. It can only exist between the sensor and the controller or between the controller and the brake [7]. There is no direct link between the sensor and the brake. If you want to trigger the sensor after the brake is complete, you need to add an attribute to the object and create a sensor for this attribute to monitor the change in properties.

\section{Conclusion}

Excellent educational game software should be the perfect unity of teaching art and technology. Through the simulation technology such as virtual reality, construct an immersive educational game situation, create a realistic inquiry environment for learners, effectively integrate the learning environment and entertainment environment, and integrate the subject knowledge into the game scene, thus benefiting the learner. At the same time, the research of this paper also shows that the planning and design of game software based on experiential learning education plays a vital role in embodying the educational nature of educational games, and should be fully paid attention to in subsequent research and application.

\section{Acknowledgement}

This project is sponsored by: the Advanced Training for Professional Major Leaders of Higher V ocational Colleges in Jiangsu Province (2017GRFX039), 3rd Education Reform Project of Vocation al Colleges in Jiangsu Province (ZYB276), Key Project of Modern Education and Technology in Jia ngsu Province(2016-R-47449), Project of Education and Science Planning in Jiangsu province(C-c/ 2016/03/38).

\section{References}

[1] X.L.Song, Construction of educational game software design pattern based on experiential learning, China's adult education, 2002, vol.10, pp.45-48.

[2] J.Q. Cheng, Comparative analysis of primary and secondary education game software at home 
and abroad, Zhejiang Normal University, 2006, vol.6, pp.32-35.

[3] H.Y. Zhang, The Creation of Exploratory Multimedia Science Courseware, Journal of Southern Yangtze University (Educational Science Edition), 2005, vol.1, pp.21-23.

[4] W.D. Chen, Thinking on the Design and Application Strategy of Educational Games, Journal of Jilin Radio and Television University, 2008, vol.1, pp.17-20.

[5] Zh.Sh. Zheng, Research on the Design of Multimedia Teaching Software Based on Constructivism, Journal of Ningbo Garment Vocational and Technical College, 2004, vol.6, pp. 96-97.

[6] X.Zh.Wang, Theoretical basis and design steps of instructional design for multimedia teaching software, Journal of Inner Mongolia University for Nationalities, 2006, vol.4, pp.22-23.

[7] H.W. Gao, Design and Practice Research of Educational Online Games, Guilin: Guangxi Normal University, 2007, vol.5, pp.43-45. 